\title{
CRITICAL REMARKS ON SIMON CANEY'S HUMANITY-CENTERED APPROACH TO GLOBAL JUSTICE
}

\author{
JULIAN CULP ${ }^{1}$ \\ (Goethe-Universität Frankfurt, Germany)
}

\begin{abstract}
The practice-independent approach to theorizing justice (PIA) holds that the social practices to which a particular conception of justice is meant to apply are of no importance for the justification of such a conception. In this paper I argue that this approach to theorizing justice is incompatible with the method of reflective equilibrium (MRE) because the MRE is antithetical to a clear separation between issues of justification and application. In particular I will be maintaining that this incompatibility renders Simon Caney's cosmopolitan theory of global justice inconsistent, because Caney claims to endorse both a humanity-centered PIA and the MRE.

Keywords: Simon Caney. Method of reflective equilibrium. Humanity. Justice. Practice-dependence. John Rawls
\end{abstract}

\section{Introduction}

One of John Rawls's (1951; 1971: 46-53; 1974; 2001: 29-32) many great achievements is his pioneering work on the method of reflective equilibrium (MRE). Rawls was the first to translate Quinean insights on the superiority of coherentist over foundationalist programs of justification from philosophy of science to moral and political philosophy. ${ }^{2}$ By now the MRE has achieved the status of the default option for doing normative moral and political theory (Daniels 2011).

In this paper I urge political philosophers and theorists to recall that the MRE includes at its core a commitment to the inseparability of the justification and application of a conception of justice. Therefore, modes of justification that deny this inseparability cannot plausibly claim to employ the MRE. Yet Simon Caney $(2005: 37,120 ; 2011)$ endorses the MRE while also employing a humanity-centered, practice-independent approach to the justification of a conception of justice (PIA). ${ }^{3}$ The latter, however, as I will argue in this paper, denies said inseparability.

Caney may object that on a restricted version of what Rawls (1974: 8) has dubbed the "wide" understanding of the MRE, the theorist need not consider the foreseeable practical implications of adopting a particular conception of justice. Different from the "narrow" (Rawls 1974: 8) understanding of the MRE, this wide understanding does not view it as 
sufficient when the theory's principles cohere with a restricted range of considered moral judgments, e.g. those about human beings' morally most significant interests. ${ }^{4}$ Rather, the principles that cohere with these judgments must also be supported by the independent appeal of a "moral background theory" (Daniels 1979: 256) such as contractualism or utilitarianism. This, in turn, requires that there is yet another, non-overlapping set of moral judgments that supports the background theory, and which makes this theory especially compelling when compared to alternative moral background theories.

In response, I argue that this restricted but wide understanding of the MRE violates the 'coherentist spirit' of the MRE. It arbitrarily excludes those particularly salient moral judgments that are evoked when assessing whether a theory of justice is of use in practice. Properly conceived, the MRE requires identifying a set of mutually supportive beliefs at all levels of generality. Hence my aim in this paper is to discipline the use of the MRE, and to criticize Caney for employing a curious mode of justification that fails to ascribe justificatory force to the foreseeable structure and shape of the practices that are meant to realize justice.

\section{Caney's humanity-centered, practice-independent approach to theorizing justice}

The distinction between a humanity-centered, PIA and a practice-dependent approach to theorizing justice (PDA) is a side-product of the contemporary debate about global distributive justice. $^{5}$ In The Law of Peoples, Rawls (1999: 115-120) criticized so-called “cosmopolitan egalitarians" (Beitz 2000: 677), according to whom some egalitarian principles of distributive justice, e.g. the "difference principle", apply among all individuals globally. ${ }^{6}$ Rawls (1999: 37, 41) argued that substantively different principles, which are meant to express egalitarian relations among well-ordered societies, should be employed for assessing and regulating global distributive justice. Initially, Rawls has been attacked harshly for taking up this position. Thomas Pogge $(2004,2006)$, for one, has claimed that Rawls' domestic and global theories of global distributive justice are incoherent. ${ }^{7}$

Soon thereafter, however, Aaron James (2005) has pointed out that one can actually make good sense of Rawls' position. ${ }^{8}$ All that is necessary for this is to recognize that Rawls justifies principles of justice in light of the central features of the practices that these principles are meant to govern. After all, Rawls (1971: 29) endorses the idea that "the correct regulative principle for anything depends on the nature of that thing". Once one acknowledges this, such as James has, it is but one small step to understand why Rawls justifies distinct principles of justice for the domestic and global orders. The global and domestic orders differ 
structurally, that is, with regard to their constitutive practices. While the global order is made up of societies, domestic orders are made up of individuals. Hence it should not come as a surprise that Rawls, accordingly, defends two distinct sets of principles of justice for these two orders and rejects the cosmopolitan extrapolation of his difference principle to the world at large.

James' work has been extremely valuable for clarifying Rawls' sensitivity to the particular shape of the social practices that Rawls's principles of justice are supposed to govern. Yet it is Andrea Sangiovanni $(2007,2008: 138)$ who has formulated the perhaps most prominent definition of this approach, which says that "the content, scope, and justification of a conception of justice depends on the structure and form of the practices that the conception is intended to govern."

By 'content of justice' Sangiovanni means the principles that express what it is that a conception of justice substantively requires. These principles may be of an egalitarian kind and call for an equal distribution of resources or opportunities. Alternately, the principles may be of a prioritarian kind and demand that resources or opportunities should be allocated first and foremost to the least well off. ${ }^{9}$ The 'scope of justice' refers to the population of people, for example states, cities, regions or the world at large, for which a particular content of justice claims validity. A conception of justice need not restrict itself to the articulation of a single content of justice for one particular population of people. It may hold that separate contents of justice apply to different populations of justice with varying scope. For example, equality of opportunity and a sufficiencitarian minimal threshold of resources may be viewed as the valid contents of justice within states and the world at large, respectively. ${ }^{10}$ The central thesis of the PDA is that the justification of the content and scope of justice is inextricably tied to the shape and features of the practices that a particular conception of justice is meant to govern. The justification of a conception of justice thus cannot abstract from or bracket these practices. $^{11}$

Ex negativo, it follows from this characterization of the PDA that according to the PIA the social practices to which a particular conception of justice is meant to apply play no role in the justification of a conception of justice. G.A. Cohen's (2008: ch. 6) recent argument that the justification of a conception of justice should not rely on any empirical facts, and thus also not on facts about social practices, is one way in which theorists can defend and adopt the PIA. 
But also the humanity-centered mode of justification that Caney uses belongs to such a PIA. For its core claim, according to Caney (2011: 507) is that "some [justice-based] entitlements inhere in persons simply as human beings." Caney admits that other justicebased entitlements may be grounded by taking into account the structure and form of the practices within which these entitlements claim validity. Yet he insists that there are some justice-based entitlements whose justifications do not draw upon a consideration of the practices within which these entitlements are supposedly valid. This humanity-centered justification thus amounts to a PIA, which is, I argue, incompatible with a proper understanding of the MRE. For the defenders of the PIA, like Caney, do not attach any justificatory weight to the practical implications of their principles of justice in their defense of these principles.

Caney's methodological commitment to a PIA is also evident in his argument that realist critiques, which doubt that international policies do reduce global socio-economic inequality could ever realize cosmopolitan principles, do not put such principles into question. Economists like Dani Rodrik (2011), for instance, are highly skeptical that economic convergence will take place in the years to come, despite the long lasting, high economic growth rates of countries like Brazil, China and India. According to Caney, such skepticism addresses the question how to implement his principles and thus does not undermine the justifiability of these principles. Caney (2005: 139) emphasizes this point, as well as his underlying commitment to a separation between issues of application and issues of justification, as follows:

They [i.e. the realist critiques] are directed against specific policies and programs but not against the moral principles. There is, then, in this sense not necessarily a value-conflict between these realist points and cosmopolitan principles of justice. This bears out the point ... of the utility of differentiating between different levels of philosophical analysis and distinguishing between claims about what fundamentally matters and claims about what particular policies should be adopted.

Issues about the application of principles of justice are separated from the issues about their justification, as if the two were totally unrelated to each other. ${ }^{12}$ In a similar vein, Tan (2004: 15) also denies the relevance of the practical implications of his cosmopolitan conception of global distributive justice for the justification of that conception:

Working out the practical and technical details of a just global distributive scheme is ... outside the domain of philosophy and best left to experts in other fields. Nonetheless we can begin to seriously consider the practical details of the 
cosmopolitan alternative to our current global order only when we are convinced of the moral force and coherence of the cosmopolitan vision.

Thus, in line with the PIA, a theorist should first of all seek to ground a conception of justice without regard to the 'practical details' that flow from an actual embracement of such a conception. Only then may he or she determine - individually or in collaboration with social scientists - the policies and social changes that are necessary so as to realize that conception of justice.

To clarify, this is not to say that proponents of the PIA are not interested in the realworld implications of their theories. Defenders of the PIA do consider, e.g. for the sake of giving advice to public policy makers, what the application of a particular conception of justice would require in practice (see Caney 2006). However, those who follow the PIA do not view these practical conclusions as relevant considerations for potential amendments to the principles based upon which these conclusions were drawn. After all, the PIA postulates that conceptions of justice are not grounded with regard to considerations that have to do with the particular form and structure of the social practices that the principles of a conception of justice are meant to govern. Only the practical conclusions themselves, regarding to what extent certain policies and institutions actually realize the already justified principles, can be contested and changed. Hence it is characteristic of the PIA, including Caney's humanitycentered approach, that it separates questions about the justification of principles of justice from those about the application of these principles. ${ }^{13}$

\section{The incompatibility of the practice-independent approach with the method of reflective equilibrium}

Caney (2005: 37) states explicitly that he is employing the MRE:

"Following Rawls, I take it that the most plausible way of engaging in this enterprise [of justifying a theory of justice] is to strive for what he terms a process of "reflective equilibrium' between moral theories and considered moral judgments."

Yet, as I will argue in this section, the PIA, which is the genus of which Caney's humanity-centered mode of justification is a type, is incompatible with a proper understanding of the MRE. The decisive reason why the PIA is incompatible with the MRE is that the former but not the latter separates the justification of principles of justice from their application. This is because, on a coherentist approach to justification, including the MRE, it 
is necessary to establish mutually supportive and consistent beliefs on the level of abstract principles as well as on the concrete levels of public policy and of individual courses of action. Hence the expected consequences that will result from adhering to certain principles of justice must be taken seriously in their justification. Along these lines Rawls (1971: 30) has stated unequivocally that it would be "crazy" to endorse normative principles without a proper acknowledgment of their consequences in practice.

According to Rawls' understanding and formulation of the MRE one does not grant plausibility to principles of justice simply because they are intuitively appealing and cohere amongst each other. Neither does it suffice if certain principles cohere with a restricted range of moral judgments that are drawn from a very restricted range of cases. Rather, such an initial, intuitive attraction to any principles, as well as the justificatory force that is drawn from their coherence with a limited range of moral judgments, has to be affirmed by examining the adoption of the principles in light of their foreseeable practical implications. That is, one needs to determine whether the foreseeable practical requirements and outcomes of certain principles of justice may provoke moral judgments that militate against their adoption. If that turns out to be the case, then one is well advised to revise the principles rather than amending the moral judgments.

Again, the reason for this is that, properly conceived, reflective equilibrium should be achieved between considerations of differing degrees of generality - including abstract principles, public policies as well as concrete courses of individual action (Rawls 2001: 30; Daniels 1996: 1-20). So it matters how normatively appealing the social reality is that would be brought about by the realization of these principles - including, among other things, the social institutions and public policies that the principles' realization requires.

As a result, employing the MRE means to blur the distinction between 'normative ethics' and 'applied ethics', as these two subject matters should not be treated separate from one another. Rather, carrying out research in applied ethics may generate certain insights that require revising the theory that one has been using for determining what is morally required within a particular context of individual or collective action. Norman Daniels (1996: 191-3), for example, has emphasized this point and suggested that determining what Rawls's conception of justice as fairness demands practically in the area of health care forces one to revise the conception itself. This is because according to Rawls's fair equality of opportunity principle people should have fair opportunities solely with regard to jobs and public offices. The principle thus neglects that fair equality of opportunity may also require having fair chances of achieving, if possible, comparable levels of normal functioning. 
By way of illustration of this crucial aspect of the MRE, recall also the way in which Rawls (2005 [1993]: ch. 7) puts into question entitlement theories like that of Robert Nozick. Rawls does not deny that the two fundamental principles of Nozick's (1974: 151) entitlement theory - i.e. the principles of just appropriation and just exchange - are intuitively or prima facie very attractive. Yet he suggests that compliance with these principles will engender extremely high levels of socio-economic inequality, which in turn do not at all seem to be normatively particularly attractive. In fact, it is questionable that just exchanges could at all take place in the long run, since once that relatively high levels of socioeconomic inequality have emerged, individuals' consent to particular transactions perhaps can no longer be viewed as (sufficiently) voluntary. So Nozick's principles of justice turn out to be practically selfdefeating. For the conditions under which the principles of the entitlement theory may appear particularly appealing, that is, conditions under which truly voluntary transactions among individuals are possible, may over time be eroded by the compliance with these principles. So whenever we have to judge whether we should endorse certain principles of justice, we have to assess the foreseeable practical implications of the adoption of these principles.

To use another example, consider why Allen Buchanan (2005: 64-8) has been reluctant to recognize the validity of a cosmopolitan conception of global justice (e.g. one that extrapolates Rawls' principles of justice as fairness to the world at large). Buchanan argued that there is insufficient reliable information regarding the practical consequences that an adoption of this conception would have. Among other things, it is unclear what kind of global political institutions would be required to realize such cosmopolitan principles. This means that it is simply impossible to evaluate whether the particular global institutional order that the realization of these principles would bring about would sit well with our moral judgments.

Thus, according to the logic of Buchanan's argument, those who endorse the MRE cannot subscribe to a cosmopolitan conception of justice as long as they do not have sufficiently reliable empirical information about what this implies practically. As long as, as Ayelet Banai et al. (2011: 52) have put it, "there is no adequate way of testing our allegiance to the [cosmopolitan] principles", a justification on the basis of the MRE cannot be carried out. If we lack the empirical information needed to test whether a given set of cosmopolitan principles of global distributive justice is compatible with our moral judgments in particular cases, a crucial element for a convincing justification of these principles is missing.

Again, those who endorse a PIA deny that the "justification of a conception of justice depends on the structure and form of the practices that the conception is intended to govern" 
(Sangiovanni, 2008: 138). Consequently, they effectively fail to ascribe any justificatory importance to the moral judgments that the foreseeable effects of the actual adoption of these principles provoke. Hence, the PIA is incompatible with the MRE, which requires taking into account such moral judgments.

\section{Why a wide but restricted reflective equilibrium is not enough}

How might Caney respond to this criticism that his humanity-centered, PIA is incompatible with the MRE? Perhaps Caney would respond that he is endorsing a wide but restricted understanding of the MRE, according to which it is not necessary to consider how appealing the practical implications flowing from the adoption of a particular conception of justice are. This wide but restricted understanding of the MRE demands only - Caney might argue - the following two things. Firstly, that one's principles of justice cohere with one's moral judgments for a well-defined, restricted range of cases. Secondly, as it is characteristic for a wide understanding of the MRE, the principles must also cohere with a moral background theory that one can support on the basis of additional moral judgments. This background theory should therefore be regarded as especially compelling when compared to alternatives.

It may suffice, for example, to pay close attention to our moral judgments regarding what we owe to human beings simply in virtue of their humanity. Based on these moral judgments we may be able to infer certain principles. Such principles would not only have to generate said judgments when we deduce from them what is owed to human beings as such, that is, irrespective of the particular kinds of social practices that they inhabit. In addition, these principles should also be supported by a moral background theory that strikes us as particularly convincing when assessed comparatively to other such theories. For example, we may have further reason to recognize the validity of these principles because they can be viewed as elements of an especially parsimonious moral background theory. In congruence with the second aspect of this method, Caney (2005: ch. 4, sect. 3, 4) shows that while contractarian and consequentialist theories also endorse cosmopolitan principles (and must therefore be viewed as compelling), their rationales for justifying these principles are less convincing than the one that an interest-theory of rights provides. ${ }^{14}$

So this second aspect provides evidence that the kind of MRE that a humanitycentered, PIA endorses is indeed a wide understanding of the MRE. After all, the principles that the humanity-centered, PIA recognizes as valid are not only compatible with the 
normative beliefs of the theorist himself, e.g. those of Caney. Rather, these principles also cohere with a moral background theory that is portrayed as compelling relative to other such moral background theories - which may stem from various cultures. Indeed, Caney (2005: 37) refers to this kind of wide understanding of the MRE when he states that "any adequate moral theory must be able to cope with the objections that others may level at it, including objections from those from different cultures."

Conceding the force of this objection at least in part, Caney's humanity-centered approach indeed represents a version of a wide understanding of the MRE. He not only seeks coherence between certain principles and his moral judgments about particular cases like the intrinsic moral importance of certain interests of human beings. This would only suffice for achieving a narrow reflective equilibrium. Caney also aspires to bring into equilibrium his principles of justice with a certain moral background theory that can be shown to be particularly compelling relative to various alternatives. Therefore, Caney may insist that there is a sense in which it is not inconsistent to embrace a humanity-centered, PIA and a wide understanding of the MRE.

This objection is not fully satisfying, however, because it still remains arbitrary not to consider those moral judgments that are provoked by assessing the foreseeable practical implications that are most likely to follow from the adoption of a particular conception of justice. The restricted but wide understanding of the MRE that the defenders of the humanitycentered PIA support is still not far-reaching enough.

One central reason for this is that often times the very meaning of certain principles remains unclear as long as their implications have not been sufficiently explained. For instance, we may wonder whether Rawls's difference principle would actually judge what appears to be an excessive degree of economic inequality as unjust. The difference principle states that economic inequalities in income and wealth are permitted as long as these inequalities maximize the share of income and wealth possessed by the least advantaged group in society. Hence, even if the difference principle is fully realized, those who are especially well endowed with natural talents may be able to exploit their endowments in ways that afford them much greater shares of the products of social cooperation (in terms of income and wealth) than the least advantaged receive. Even if the least advantaged would be worse off in the absence of these inequalities, the inequalities themselves may be judged, on reflection, as unjust and therefore may put into question the validity of the difference principle. 
Yet what level of inequality may permissibly result from regulating society's basic structure in accordance with the difference principle is to a large degree an empirical question. To see this, consider that when responding to this question about the degree of inequality that the difference principle allows, it is necessary to appreciate the conditions under which the difference principle is deemed to be of practical importance. For given the lexical ordering of Rawls's three principles of justice, the difference principle is only granted validity once that the equal liberties principle and the fair equality of opportunity principle already have been fully satisfied (cf. Rawls 2001: 67, n. 37). Accordingly, excessively high levels of inequality are extremely unlikely to arise when the societal basic structure is regulated by the difference principle. This is because the economic inequalities generating effects of individuals' social backgrounds will not compound the inequalities that are derivative of individuals' differentials in natural endowments. Hence, once advantages in opportunities no longer derive from social privileges, there will be considerable competition from a significant pool of wellqualified applicants for any job. This, in turn, will prevent the emergence of particularly pronounced economic inequalities that would otherwise occur. For it is only in the absence of sufficient competition that a small number of socially privileged, naturally talented, and welltrained individuals could form oligopolies and set whatever prices they want for their labour. Hence once the fair equality of opportunity principle is realized, and the distribution of income and wealth is regulated by the difference principle, it is very difficult to argue that the difference principle permits excessively high levels of economic inequality. This example thus illustrates that understanding what kind of distribution a particular principle assesses as just may sometimes require analyzing how such a principle operates in practice. Accordingly, judging the foreseeable practical implications of a conception of justice is, or so it seems, a sine qua non of any justification of justice that relies on the MRE.

\section{Conclusion}

In this paper I have argued that Caney's humanity-centered, PIA is incompatible with a properly conceived version of the MRE, despite Caney's explicit endorsement of the MRE. Caney embraces what I have termed a wide but restricted understanding of the MRE, which does not view the foreseeable consequences of adopting a conception of justice as relevant data points, so to speak, for assessing the validity of such a conception. It focuses solely on the moral judgments regarding certain interests of human beings. Hence, Caney's use of the MRE does not include an evaluation of the practices that should eventually realize justice. 
This justificatory method is in line with the PIA, according to which the structure and form of the practices that a conception of justice is intended to govern play no role in the justification of that conception. However, the wide but restricted MRE thereby fails to follow through on the coherentist logic of the MRE. For this logic impels the theorist to achieve coherence among beliefs at all levels of generality. This requires, as I have argued, taking a stance as to whether supposedly well-justified principles of justice are of any use in practice. A sound version of the MRE thus refrains from drawing a sharp line between justifying and applying a particular conception of justice. To the extent that Caney's humanity-centered approach to theorizing justice, by contrast, is supportive of such a division, it does not sit well with the coherentist dynamic envisioned by the MRE.

By way of conclusion, I would like to highlight the internal character of my argument. I did not argue that Caney should employ the MRE, and that he should therefore refrain from employing the humanity-centered, PIA. Rather, I have argued that because Caney endorses the MRE, he should not also embrace the humanity-centered, PIA. So Caney may decide to drop his endorsement of the MRE but continue using the humanity-centered, PIA. Nothing I have said in this paper defended the view that theorists must subscribe to the MRE.

\footnotetext{
Acknowledgments

I presented earlier versions of this paper at a research seminar of the Centre for Advanced Study Justitia Amplificata: Rethinking Justice - Applied and Global at the University of Frankfurt in June 2011 and at the Society of Fellows Weissbourd Spring Conference Theory and Practice at the University of Chicago in May 2015. I would like to thank the audiences at these events for their valuable comments. I would also like to thank Ayelet Banai, Joseph Carens, Anna Goppel, Stefan Gosepath, Joseph Heath, Miriam Ronzoni and Christian Schemmel, in particular, for their very helpful comments. I benefitted from the Postdoctoral Fellowship in Normative Theory from the Centre for Ethics at the University of Toronto while wiritng this paper.
} 


\section{Notes:}

${ }^{1}$ Research Associate in the Leibniz Research Group Transnational Justice at the University of Frankfurt, Frankfurt, Germany. E-mail: Culp@em.uni-frankfurt.de

${ }^{2}$ Note, however, that Nelson Goodman's (1955: 63-66) work on rules for drawing correct inferences and making proper deductions involved the idea of balancing abstract principles and concrete judgments, which in turn inspired Rawls's formulation of the method of reflective equilibrium.

${ }^{3}$ David Richards (1982), Charles Beitz (1983), Allen Buchanan (1990) and Darrel Moellendorf (2002: 24) also defend a humanity- or subject-centered approach to the justification of certain principles of justice. I leave it for another occasion to assess to what extent their theories may also be subject to a charge similar to the one put forward in this paper.

${ }^{4}$ In the following, I will always mean considered moral judgments when referring simply to moral judgments. The qualifier 'considered', which I will subsequently drop, means that the moral judgment is made on reflection, not under duress, and by a person in adulthood with adequate information.

${ }^{5}$ Jubb (2014) also identifies earlier, PDAs in the works of Peter Strawson and Bernard Williams. Ibsen (2013) highlights that Jurgen Habermas and Axel Honneth's method of normative reconstruction is congenial to the PDA. Honneth (2014) and Iser (2016) offer an explanation and discussion of this method.

${ }^{6}$ Rawls's domestic conception of justice as fairness consists of the equal basic liberties principle, the fair equality of opportunity principle, and the difference principle; see Rawls (2001: 42-3) for the final formulation of these principles.

${ }^{7}$ See also (Buchanan 2000) for a harsh but still more charitable critique.

${ }^{8}$ Leif Wenar (2004), Samuel Freeman $(2006,2007)$ and Huw Williams (2012) have also emphasized the coherence of Rawls's domestic and international theories of justice.

${ }^{9}$ See Parfit (1997) on the distinction between prioritarian and egalitarian principles of justice.

${ }^{10}$ See Frankfurt (1987) for a defence of a sufficientarian account of justice, arguing that from the point of view of distributive justice it matters most that people have enough.

11 Arguably, however, practice-dependent theorists may idealize certain practices by focusing selectively on some of their features. Rawls, for example, understands a liberal society's constitutive practice as one that is cooperative in nature, and thus is guided by a certain ideal of reciprocity. In this way the PDA relies not solely on the descriptive characterization of social practices but also involves an interpretative task. This interpretative task has at its goal to normatively reconstruct the guiding values that implicitly orient the people who form these practices.

${ }^{12}$ Caney (2005: 3) at another point also emphasizes that "the application of principles to specific issues ... can be performed only by integrating principles ... with an enormous amount of empirical detail and by concentrating on specific issues in a case-by-case way", but he also clarifies that his work primarily "seeks to identify what principles should be applied at the global level", rather than dealing with specific issues.

${ }^{13}$ In a similar fashion, Gunther (1993) has also argued for the separation between moral and legal discourses of justification and of application.

${ }^{14}$ Caney (2005: 120) endorses explicitly a Razean interest theory of rights: "When we think about the rights people treasure most-like the right not to be tortured or the right to freedom of belief-we can see that these rights protect interests people value highly. Any credible account of people's rights reflects what is important to persons - their fundamental interests.” 


\section{Bibliographical references:}

Banai, Ayelet, Miriam Ronzoni, and Christian Schemmel. 2011. 'Global Social Justice.' In Ayelet Banai, Miriam Ronzoni, and Christian Schemmel (eds), Social Justice, Global Dynamics. London: Routledge, 46-60.

Beitz, Charles. 1983. 'Cosmopolitan Ideals and National Sentiment.' Journal of Philosophy, 80 (10), 591-600.

Beitz, Charles. 2000. 'Rawls's Law of Peoples.' Ethics, 110 (4), 669-96.

Buchanan, Allen. 1990. 'Justice as Reciprocity versus Subject-Centered Justice.' Philosophy and Public Affairs, 19 (3), 227-52.

Buchanan, Allen. 2000. 'The Law of Peoples: Rules for a Bygone Westphalian Order.' Ethics, 110 (4), 697-721.

Buchanan, Allen. 2004. Justice, Legitimacy and Self-Determination. New York: Oxford University Press.

Caney, Simon. 2005. Justice Beyond Borders. Oxford: Oxford University Press.

Caney, Simon. 2006. 'Cosmopolitan Justice and Institutional Design: An Egalitarian Liberal Conception of Global Governance.' Social Theory and Practice, 32, 725-56.

Caney, Simon. 2011. 'Humanity, Associations and Global Justice: A Defence of HumanityCentred Cosmopolitan Egalitarianism.’ The Monist, 94 (4), 506-34.

Cohen, G. A. 2008. Rescuing Justice and Equality. Cambridge, Mass.: Harvard University Press.

Daniels, Norman. 1979. 'Wide Reflective Equilibrium and Theory Acceptance in Ethics.' Journal of Philosophy 76 (5), 256-82.

Daniels, Norman. 1996. Justice and Justification. Reflective Equilibrium in Theory and Practice. Cambridge: Cambridge University Press.

Daniels, Norman. 2011. 'The Method of Reflective Equilibrium.' In Edward Zalta (ed.), The Stanford Encyclopedia of Ethics. http://plato.stanford.edu/ (home page). Accessed November $14,2012$.

Frankfurt, Harry. 1987. 'Equality as Moral Ideal.’ Ethics 98, 21-43.

Freeman, Samuel. 2006. 'Distributive Justice and the Law of Peoples.' In Rex Martin and David Reidy (eds), The Law of Peoples: A Realistic Utopia? Malden: Blackwell, 243-59. 
Freeman, Samuel. 2007. 'The Law of Peoples, Social Cooperation, Human Rights and Distributive Justice.' In Samuel Freeman, Essays in Rawlsian Political Philosophy. New York: Oxford University Press, 259-95.

Goodman, Nelson. 1955. Fact, Fiction and Forecast. Cambridge, Mass.: Harvard University Press.

Gunther, Klaus. 1993. The Sense of Appropriateness. Application Discourses in Morality and Law. Albany: SUNY Press.

Honneth, Axel. 2014. Freedom's Right. The Social Foundations of Democratic Life. New York: Columbia University Press.

James, Aaron. 2005. 'Constructing Justice for Existing Practice: Rawls and the Status Quo.' Philosophy and Public Affairs, 33 (3), 281-316.

Ibsen, Malte. 2013. 'Global Justice and Two Versions of Practice Dependence.' Raisons Politiques 51 (3), 81-96.

Iser, Mattias. 2016. Indignation and Progress. Foundations of a Critical Theory of Society. Oxford: Oxford University Press.

Jubb, Robert. 2014. "Recover it from the Facts as we Know Them": Practice-Dependence's Predecessors.' Journal of Moral Philosophy. 1-23.

Moellendorf, Darrel. 2002. Cosmopolitan Justice. Boulder: Westview Press.

Nozick, Robert. 1974. Anarchy, State and Utopia. New York: Basic Books.

Parfit, Derek. 1997. 'Equality and Priority.' Ratio 10 (3), 202-21.

Pogge, Thomas. 2004a. 'The Incoherence of Rawls's Two Theories of Justice.' Fordham Law Review, 72 (5), 1739-59.

Pogge, Thomas. 2006. 'Do Rawls's Two Theories of Justice Fit Together?' In Rex Martin and David Reidy (eds), Rawls's Law of Peoples: A Realistic Utopia? Malden: Blackwell, 206-25.

Rawls, John. 1951. Outline of a Decision Procedure for Ethics. Philosophical Review 60 (2), 177-197.

Rawls, John. 1971. A Theory of Justice. Cambridge, Mass.: Harvard University Press. Rawls, John. 1974. 'The Independence of Moral Theory.' Proceedings and Addresses of the American Philosophical Association 47: 5-22.

Rawls, John. 1999a. The Law of Peoples. Cambridge, Mass.: Harvard University Press.

Rawls, John. 2001. Justice as Fairness. Erin Kelly (ed.). Cambridge, Mass.: Harvard University Press. 
Rawls, John. 2005 [1993]. Political Liberalism. Expanded Edition. New York: Columbia University Press.

Richards, David. 1982. 'International Distributive Justice.' In J. Roland Pennock and John W. Chapman (eds), Nomos 24: Ethics, Economics, and the Law. New York: New York University Press, 275-99.

Rodrik, Dani. 2011. 'The Future of Economic Convergence.' National Bureau of Economic Research Working Paper 17400. http://www.nber.org/papers/w17400.pdf

Sangiovanni, Andrea. 2007. 'Global Justice, Reciprocity, and the State.' Philosophy and Public Affairs, 35 (1), 3-39.

Sangiovanni, Andrea. 2008. 'The Priority of Politics over Morality.' Journal of Political Philosophy, 16 (2), 137-64.

Tan, Kok-Chor. 2004. Justice Without Borders. Cambridge: Cambridge University Press.

Wenar, Leif. 2004. 'The Unity of Rawls's Work.' Journal of Moral Philosophy, 1 (3), 26575.

Williams, Huw-Lloyd. 2012. Rawls, Development and Global Justice. Basingstoke: Palgrave Macmillan. 